\title{
The comparison of surface roughness value of microfilled and nano particle composite restoration that polish using rubber cups
}

\author{
Gita Retyoningrum, Rizki Yuli Amanda, H.D. Adhita Dharsono*, \\ Renny Febrida** \\ *Department of Conservative Dentistry Faculty of Dentistry Universitas Padjadjaran \\ **Department of Dental Material Science and Technology Faculty of Dentistry Universitas Padjadjaran
}

\section{ABSTRACT}

Surface roughness composite restoration can decrease aesthetic aspect of composite restoration and facilitated bacterial retention. It can affected periodontal disease and recurrent caries. Polishing is a process to obtain a smooth and glossy surface of restoration. Rubber cups is one of polishing instrument that frequently used to get a smooth, glossy and aesthetic surface of restoration. The specimen was microfilled (3M ESPE Z100'M Restorative, St. Paul) and nano particle (3M ESPE Z350 TM Restorative, St. Paul) composite resin blocks sized $5 \times 5 \times 2 \mathrm{~mm}$. Each of composite consist of ten specimens that polished with rubber cups for 30 seconds at $3500 \mathrm{rpm}$. Surface roughness was measured five times for each specimen by using surface roughness tester. Average Ra value of microfilled was $0.22 \mu \mathrm{m}$ and Ra value of nano particle was $0.25 \mu \mathrm{m}$. Data was analyzed by using independent t test at a 0.05 significance level and showed statistically significant differences. The conclusion of this experiment showed that surface roughness value of microfilled composite resin was smaller than nano particle composite resin restoration. A small amount of filler particle $(50.6 \% \mathrm{wt})$ made microfilled easier to polish and made a smooth surface restoration. Nano particle composition has more filler particle amount $(78.5 \% \mathrm{wt})$, and hard zirconia filler that difficult to polish than silica colloidal filler in microfilled composite resin.

Key words: Surface roughness, microfilled and nano particle composite resin, rubber cups

\section{INTRODUCTION}

Teeth are hard tissues which are located in oral area. Oral and dental health is an important matter that has to be taken care of, since teeth not only function as tools for chewing but also have influence in someone's appearance, primarily the anterior teeth. Anterior teeth have more esthetic value than their function as chewing tools. Consequently, there are some requirements in conducting anterior restoration so that the esthetic aim can be reached well, like anatomy shape and color that fit the original teeth, maximum smoothness of restoration surface, and a good contact spot. ${ }^{1,2}$

An esthetic material is needed in order to restore the esthetic function of anterior teeth. One of esthetic restoration materials for anterior 
teeth is composite resin that has been developed since 1950. In the beginning of its use, composite only used in anterior area, the area where only esthetic part was needed, while its physic nature has not been able to stay for chewing energy. ${ }^{3,4}$

Based on the condition, many studies have been conducted in order to repair the natures, so that composite is not only used as a material for anterior teeth restoration but also as a chosen material in conducting posterior restoration. Based on the size of its filling material particle, composite is divided into several types, they are macrofilled composite, microfilled composite, hybrid composite, and the latest is nano particle composite.

The composite mostly used for anterior restoration is macrofilled composite. This composite uses silica colloidal particle as its anorganic filling material with the average size of individual particle is 0.01-0.05 $\mu \mathrm{m}$. In addition, macrofilled composite has more amount of matrix than filling material particle. The amount of matrix in macrofilled composite is approximately $50-60 \%$ in weight or $32-50 \%$ in volume. Large amount of matrix makes composite has smooth surface..$^{3,5,6}$

Nano particle composite is one of the chosen materials in conducting posterior teeth restoration. The filling material is Zirconia Silica size $5-20 \mathrm{~nm}$ that comprises nanomeric and nanocluster particles. The content of the filling material particle of high nano particle is $78.5 \%$ in weight. ${ }^{5,7,8}$ Composite with high filling material particle has higher physic and mechanic natures. On the other hand, clinically, composite resin with lower filling material particle is easier to produce a smooth and glossy surface during polishing process. $^{9}$

Polishing in composite restoration is conducted for two reasons, eliminating composite extra and adjusting occlusal of a restoration by using rotary instruments. ${ }^{10}$ Another aim of polishing is to get a more smooth and glossy surface. Surface disorder as the result of no or imperfect polishing may cause plaque retention, gingival irritation, and recurrence carries. Consequently, all restorations should have a polishing in order to avoid those risks. ${ }^{11-13}$

Rubber cup is one of polishing tools that is used for composite restoration polishing. This tool is a round polishing tool that has to types, gloss polisher (yellow) and high-gloss polisher (blue). ${ }^{7}$

\section{MATERIALS AND METHODS}

The materials and tools that were used in this research were microfilled composite (ESPE $\mathrm{Z} 100^{\mathrm{TM}}$ Restorative, St. Paul) and nano particle composite (3M ESPE Z350'M Restorative, St. Paul), mylar strips (Kemdent, UK), glass slab, Halogen Light Curing Litex 680Å (Dentamerica, USA), time recorder, polisher rubber cups, yellow and blue (Kenda Polishers, Liechtenstein), mikromotor (Strong 207B, Korea), Surface Roughness Tester (Surftest SJ-301 Mitutoyo, Jepang), and Scanning Electron Microscope (SEM). ${ }^{8}$

In this research, there were 20 specimens size $5 \times 5 \times 2 \mathrm{~mm}$, and they were divided into 10 microfilled specimens and 10 nano particle composite specimens. These specimens were made by placing red candles size $5 \times 5 \times 2 \mathrm{~mm}$ in the middle of PVC pipe covered by glass slab. Then, decorative resin was poured down into the pipe until it ossified, and after that, the red candles were cleaned up so it formed a mould $(5 \times 5 \times 2 \mathrm{~mm})$ that would be filled by composite. Before radiation (20 seconds for nano particle and 40 seconds for microfilled), the composite was plated by mylar strip so the surface would be smooth and it was also plated by $2 \mathrm{~mm}$ glass slab to flatten radiation distance and speed (3500 rpm) for 30 seconds to each rubber cup (the yellow first, continued to the blue ones). ${ }^{14,15}$

The surface roughness score test using Surface Roughness Tester was conducted after the specimens were left out for 24 hours in order to get an optimum polymerization. ${ }^{3}$ The test was conducted by attaching stylus' tip to composite specimen surface, and then the surface roughness tester tool would move for $0.8 \mathrm{~mm}$ on the specimens' surface. There were 5 test for each surface on different spots so the average of composite restoration surface roughness score $(\mathrm{Ra})$ would be attained.

All of the average score of surface roughness was tested statistically by using the $t$ independent statistic test. In order to give the data visually on composite surface, Scanning Electron Microscope (SEM) was conducted to the specimens with the lowest Ra score on each composite. 
RESULT

The result of the research on comparison roughness score of polished macrofilled composite restoration surface and nano particle using rubber cups can be seen in the Table below:

Table1. Comparison roughness score of polished macrofilled composite restoration surface and nano particle using rubber cups

\begin{tabular}{ccc}
\hline \multirow{2}{*}{ No } & \multicolumn{2}{c}{ Comparison roughness $(\mathrm{Ra}, \mu \mathrm{m})$} \\
\cline { 2 - 3 } & Nano particle & Microfilled \\
\hline 1 & 0,17 & 0,24 \\
2 & 0,28 & 0,18 \\
3 & 0,15 & 0,19 \\
4 & 0,27 & 0,26 \\
5 & 0,20 & 0,33 \\
6 & 0,28 & 0,33 \\
7 & 0,28 & 0,19 \\
8 & 0,29 & 0,17 \\
9 & 0,28 & 0,14 \\
10 & 0,27 & 0,18 \\
\hline Average & 0,25 & 0,22 \\
\hline
\end{tabular}

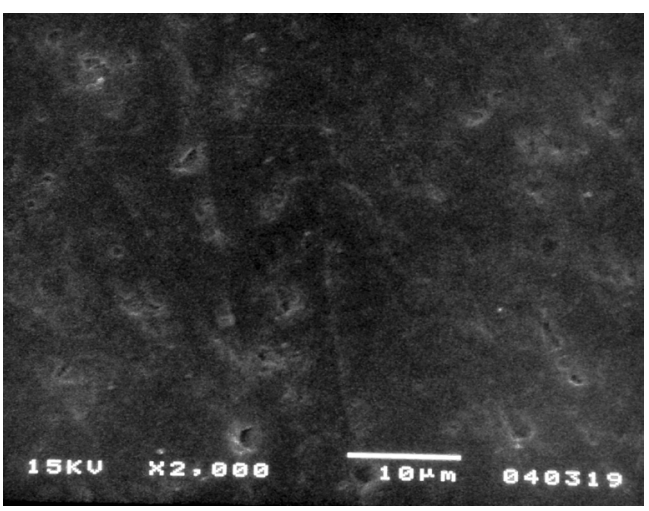

Figure 1. The result of SEM of polished nano particle composite surface using rubber cups.

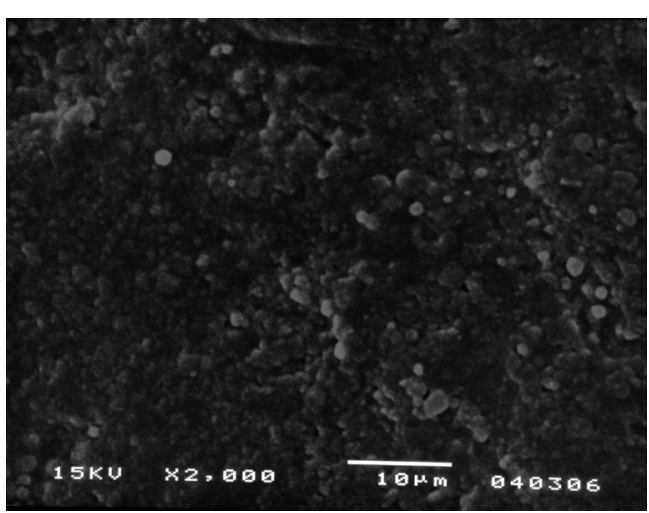

Figure 2. The result of SEM of polished microfilled composite surface using rubber cups.

\section{DISCUSSION}

The result showed that macrofilled resin composite has Ra average score $0.22 \mu \mathrm{m}$, while nano particle composite had Ra average score 0.25 $\mu \mathrm{m}$. According to the result, the surface of nano particle composite was rougher than macrofilled composite, but based on the surface smoothness measure, as indicated by Attar and Chung ${ }^{16,17}$, a restoration is regarded as smooth when the surface roughness score is less than $1 \mu \mathrm{m}$, and approaches the enamel Ra score $0.64 \mu \mathrm{m}$ so in this research, the result of $\mathrm{Ra}$ for each composite is categorized into smooth restoration surface.

Particles' size and filling material particles' distribution will affect the nature of the produced composite from all sides; strength, surface roughness, polishing result, endurance, and handling procedure.4,14,18 Filling material particle of macrofilled composite is $0.01-0.05 \mu \mathrm{m}$ in size, and it is produced from silica forging. This filling material is used for $50-60 \%$ in weight and $32-50 \%$ in volume. ${ }^{4,7}$

Small size of filling material particle of macrofilled composite may cause the composite creates very good polishing result. This is in line with Neo and $\mathrm{Yap}^{18}$, the smaller the size of filling material in a composite, the result of the polishing will be smoother and glossier. The use of small filling material may also cause macrofilled composite has very good translucency, so it gives a very esthetic result. $9,16,19,20$ The amount of matrix in macrofilled composite is approximately between $50-70 \%$ in volume. ${ }^{5,7}$ The numerous amount of matrix causes the composite has smooth surface. ${ }^{21,22}$

The development of new type of composite, nano particle composite, is also conducted based on the difference of the size, the amount and the distribution of filling material particle. Nano particle composite resin has small filling material particle scale in nanometer $(0.1-100 \mathrm{~nm}) .{ }^{9}$ The change in size and content of filling material particle in this composite is aimed to enhance its physical and mechanical natures, namely enhancing strength, hardness, elasticity modulus and endurance and also reducing polymerization shrink, expansion thermal coefficient and water absorbance. ${ }^{9,23,24}$

Commonly, nano particle composite comprises two types of filling material particle, 
nanomeric particle and noncluster. Nanomeric particle is nonagglomerate silica nano particle that is spread with the particle size 20-75 nm. Noncluster particle is agglomerate particle in nano size with loose bound between particles, size 0.6 $\mu \mathrm{m} .{ }^{8,9}$ The combination of both particles in nano particle composite is aimed to reduce the space between filling material particle. This combination also causes the ability of filling material particle in holding burden enhances, better physical nature, and enhancing retention on polishing compared to microparticle composite resin. ${ }^{9}$ In clinical application, hardness may determine the ability to polish because it will be easier to produce smooth and glossy surface, ${ }^{9}$ and will also enhance endurance on abrasion. ${ }^{25}$

During polishing using abrasive material, some filler particles of each composite type, whether it is microfilled, hybrid, or nano particle will detach from resin matrix and leave blank between resin matrix. But, since the size of filler particle of nano particle composite is very small, the blank in resin matrix will create damage on very small surface. The blank, as the result of the detachment filler particle from resin matrix, is smaller than the length of visible ray wave (0.4$0.8 \mu \mathrm{m}$ ) so human eyes sight cannot detect it. The detachment of filler particle from resin matrix nano particle composite will not affect roughness and glossiness of surface..$^{9,23}$

Some studies that compare surface roughness between nano particle composite and macrofilled and hybrid composites show significant result. They stated that nano particle composite surface produced quite smooth surface compared to the other. The research conducted by Attar ${ }^{16}$ created significant Ra score, $0.02 \mu \mathrm{m}$ for nano particle composite (Filtek Supreme E), $0.03 \mu \mathrm{m}$ for microfilled (Filtek A-110) and 0.03 $\mu \mathrm{m}$ Microhybrid (Artemis). The Ra score was got from the polymerized surface under mylar strip. The research conducted by Turssi CP et al. ${ }^{26}$ which compared surface roughness score between nano particle composite and microfilled also gave different Ra scores.

The SEM result from the research conducted by Mitra et al. ${ }^{9}$ indicated that surface roughness after 500 times abrasive teeth brushing cycle treatment was given showed a significant result. That was, nano particle composite was smoother compared to microfilled and hybrid composites.

The ability of microfilled composite restoration material in forwarding ray will create blur vision when filler particle and resin matrix are not balanced in bias index. This happens as the result of disorder ray spread of big filler particle that in line with the length of visible ray wave. In scale $10^{-9}$ meter, nano particle is a tiny size. When nano particle composite touches by visible ray with higher wave length than its filler size, it cannot be detected, so human eyes sight will not be able to detect the existence of the nano particle. The tiny size of the filler also affects on the optic of a material in order to produce high translucency. ${ }^{9,16,27}$

Surface roughness test using surface roughness tester, this test instrument measures Ra (surface roughness score) in micron scale. Nano particle composite has smaller filler size than test instrument, which is in nano scale $\left(10^{-3}\right.$ micron). But, since nano particle composite consists of two types of filler particle structure, they are nanomeric and nanocluster, it is possible to conduct surface roughness test using the test instrument. Nanocluster particle type is the agglomeration of nano particle which has loose bound between its particles in 0,6 $\mathrm{mm}$ micron scale. The blank in resin matrix caused by the detachment of nanocluster filler particle may cause the test instrument stylus (probe) able to detect a slope in micro scale.

Besides surface roughness score $(\mathrm{Ra})$ got from the test result using surface roughness tester, the result of SEM below shows that unpolished surface (mylar strip) produces smoother surface. But when both of them are compared, they do not indicate any significant differences, since the size of nano scaled particle of nano particle composite is smaller than the length of visible ray wave. Based on the SEM result, it can be seen that the agglomerated particles are between the welldistributed nanomeric particles in resin matrix. In the polished SEM result, there are micron scaled nanocluster particles that are detached from matrix, so it leaves blank in resin matrix. This microscaled blank can be detected by the stylus of surface roughness tester tool.

Based on the discussion, to conduct nano particle composite restoration where the damage is in the area in which polishing using rubber polisher is difficult to reach (proximal), mylar 
strip can be used in order to have smooth and glossy surface.

\section{CONCLUSION}

Based on the result, surface roughness score of microfilled composite surface is smaller than nano particle composite. The amount of composite filler particle which is smaller than microfilled composite (50-60\% in weight) may cause the composite is easier to polish and may produce smooth restoration surface. On the other hand, nanoparticle composite has more filler particle (78.5\% in weight) and very hard Zirconia filling material particle is more difficult to polish than colloidal silica particle in microfilled composite. Numerous matrix in microfilled composite compared to nano particle composite also affect the minimum surface roughness score in microfilled composite. This may happen due to matrix that has very smooth consistency compared to filler particle.

\section{REFERENCES}

1. Baum L, Phillips RW, Lund MR. Buku ajar ilmu konservasi gigi. $3^{\text {th }}$ ed. Jakarta: EGJ; 1997. p. 251-306.

2. Lea, Febiger. Esthetic dentistry: a clinical approach to techniques and materials. Philadelphia: Library of Congress Cataloging in Publication Data; 1993. p. 39-43.

3. Craig RG, Powers JM. Restorative dental materials. $11^{\text {th }}$ ed. St. Louis: Mosby Inc.; 2002. p. 232-53.

4. Gladwin M, Bagby M. Clinical aspects of dental materials. Philadelphia: Lippincot Williams and Wilkins; 2000. p. 99-125.

5. Roberson TM, Heymann HO, Swift EJ. The art and science of operative dentistry. $5^{\text {th }}$ ed. St. Louis: Mosby; 2006. p. 495-526.

6. Mount GJ, Hume WR. Preservation and restorative of tooth structure. London: Mosby International Ltd.; 1998.

7. Anusavice, Kenneth J. Phillip's science of dental material. $10^{\text {th }}$ ed. St. Louis: W.B. Saunders Co.; 2003. p. 351-76,399-439.

8. 3 M ESPE. Technical product profile filtek $Z 350$ restorative system. USA: 3M ESPE; 2005.

9. Mitra SB, Wu D, Holmes BN. An application of nanotechnology in advanced dental materials. J Am Dent Assoc 2003;134:1382-90.

10. Jung $M$, Wehlen $O$, Klimek J. Finishing and polishing of indirect composite and ceramic inlays in-vivo: Occlusal surfaces. Oper Dent 2004;29(2):131-41.

11. Chan KC, Fuller JL, Hormati AA. The ability of foods to stain two composite resins. J Prosthet Dent 1980;43(5):542-45.

12. Heintze SD, Forjanic M, Rousson V. Surface roughness and gloss of dental materials as a function of force and polishing time in vitro. $J$ Dent Mat 2006;22:146-65.

13. Yap AUJ, Yap SH, Teo CK, Ng JJ. Finishing/ polishing of composite and compomer restoratives: effectiveness of one-step systems. Oper Dent 2004;29(3):275-9.

14. Aschheim KW, Dale BG. Esthetic dentistry: a clinical approach to techniques and materials. $2^{\text {nd }}$ ed. St. Louis: Mosby Inc.; 2001. p. 69-76.

15. Watanabe T, Masashi M, Takamizawa T, Kurokawa H, Rikuta A, Ando S et al. Influence of polishing duration on surface roughness of resin composites. J Oral Sci 2005;47(1):21-5.

16. Attar N. The effect of finishing and polishing procedures on the surface roughness of composite resin materials. J Contempor Dent Pract 2007;8(1):27-33.

17. Chung RG. Effects of finishing and polishing procedures on the surface texture of resin composites. Dent Mater 1994;10(5):325-30.

18. Neo JCL, Yap AUJ. Composite resin. in: Mount GJ, Hume WR (editors). Preservation and restoration of tooth structure. Sandgate, Queensland Aust: Knowledge Books and Software; 2005.

19. Crispin BJ, Hewlett ER, Jo YH, HoboS, Hornbook DS. Contemporary esthetic dentistry: practice fundamental. London: Quintessence Publishing Co., Ltd.; 1994.

20. Hidayat T. Aplikasi resin komposit masa kini untuk membangun restorasi estetis dan tahan lama. J Kedokt Gigi 2005;17(4):140-5.

21. St-Georges AJ, Bolla M, Fortin D, MullerBolla M, Thompson JY, Stamatiades PJ, et al. Surface finish produced on three resin composites by new polishing systems. Oper Dent 2005;30(5):593-7.

22. Türkün $L S$, Türkün $M$. The Effect of one step polishing system on the surface roughness 
of three esthetic resin composite materials. Oper Dent 2004;29(2):203-11.

23. Terry DA. Direct applications of a nanocomposite resin system: part 1-the evolution of contemporary composite materials. Los Angeles: UCLA; 2004.

24. Fortin D, Vargas MA. The spectrum of composites: new techniques and materials. JADA 2000;131(6):26-30.

25. Xu HHK, Quinn JB, Giuseppetti AA. Wear and mechanical properties of nano-silicafused whisker composites. J Dent Research 2004;83(12):930-5.

26. Turssi CP, Ferracance JL, Serra MC. Abrassive wear of resin composites as related to finishing and polishing procedures. J Dent Mater 2005. 21:641-8.

27. O'Brien WJ, Gunnar R. An outline of dental materials and their selection. Philadelphia: W.B. Saunders Co.; 1978. 